\title{
Tensile Strength Tests for Concrete and Fibre Reinforced Concrete
}

\author{
Martin Tipka ${ }^{1, a^{*}}$, Jitka Vašková ${ }^{1, b}$ and Jan Vodička ${ }^{1, c}$ \\ ${ }^{1}$ Faculty of Civil Engineering, Czech Technical University in Prague, \\ Thákurova 2077/7, Prague, Czech Republic

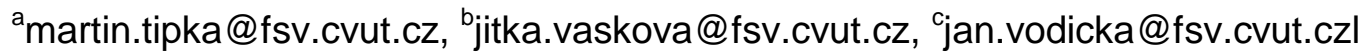

Keywords: Concrete, Fibre Reinforced Concrete, Tensile Strength, Strain, Test Methods

\begin{abstract}
The paper describes the differences in several test methods, which are used for tensile strength analysis of cementitious composites. It explains tests arrangement, their benefits and disadvantages. The conversion factors between detected strengths were quantified in experiments, depending on the particular composition of the composite.
\end{abstract}

\section{Introduction}

Here are several tests which are using for determining and verifying the tensile strengths of cementitious composites in practice. These tests vary in the form of specimens, technical difficulty and the range of outputs. Each of tests has benefits these can prefer this one to another test in specific case. The choice of a specific test arrangement is given by requirements on the results and technical possibilities of laboratory. The test outputs can be material tensile strength at macrocracking, values of residual tensile strengths in particular strain or continuous recording of stress-strain dependence. Depending on the type of used test there are tensile splitting strength, flexural strength and uniaxial tensile strength. The values of these parameters are different and can't be arbitrarily changed. Conversion factors, which are calibrated for each different recipe, are used for comparison of tests.

\section{Splitting test}

Splitting test is technically less difficult test for determining the tensile strength of cementitious composites. It is standardly realized on cube-shaped specimens $150 \times 150 \times 150 \mathrm{~mm}$ or on cylindrical specimens with diameter of $150 \mathrm{~mm}$ and high of $300 \mathrm{~mm}$. The specimen is loaded by compression force, which is equally distributed on the opposite surfaces of specimen. Standard loading rate (increase of splitting stress) is $0.04-0.06 \mathrm{MPa} / \mathrm{s}$ [1].
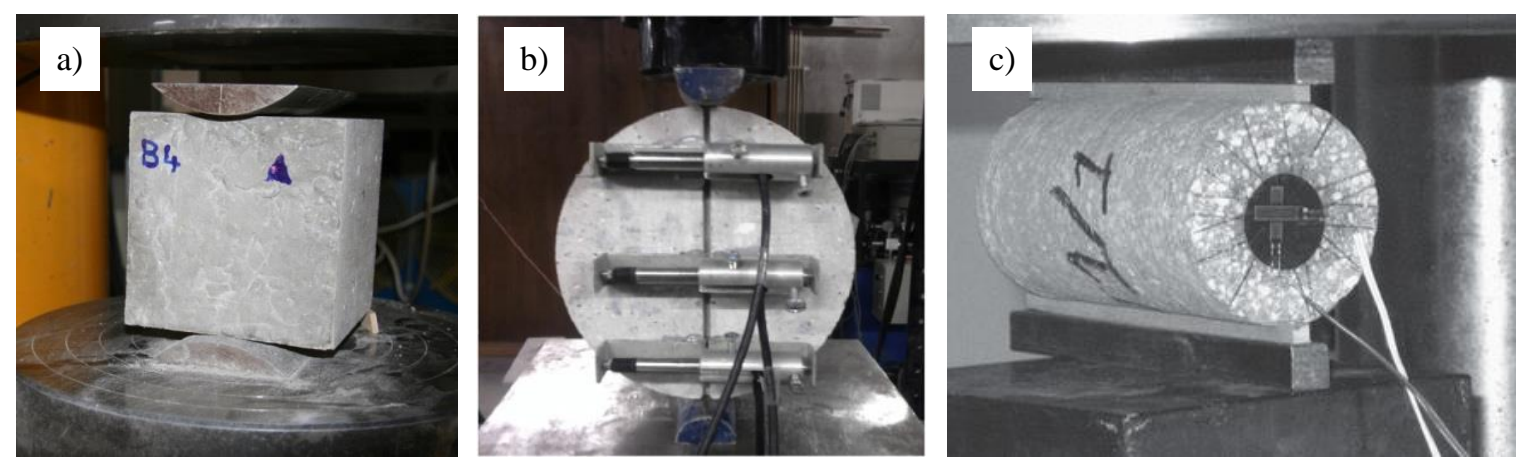

Fig. 1 Variants of splitting test arrangement [2]

The material tensile splitting strength determined on cubes is given by:

$f_{\text {fct }, \text { sp }, \text { cube }}=\frac{2 \cdot F}{\pi \cdot a^{2}}$, 
strength determined on cylinders is given by:

$$
f_{\mathrm{fct}, \mathrm{sp}, \mathrm{cyl}}=\frac{2 \cdot F}{\pi \cdot d \cdot h}
$$

where $F$ is value of load force at macrocracking, $a$ is length of cube edge, $d$ is diameter of cylinder and $h$ is height of cylinder.

The advantage of this test is speed and simplicity of execution. The routine test arrangement is suitable for demonstration of conformity in production control, but it isn't sufficient for structural design, because it doesn't provide any information about material deformation behaviour. For this purpose it is necessary to install the surface deformation sensors (Fig. 1b,c) and then it is possible to record load force - transverse deformation dependence. If the test is controlled by an increase of transverse deformation, it is also possible to record the residual part of load force - deformation diagram after macrocracking.

A certain disadvantage of the test is a low value of load force at macrocracking. This load force is many times lower than the industrial presses use. Therefore the reading of load force value can be very inaccurate (up to tens of percent).

\section{Bending tests}

Three-point bending test. Standards fib [3] and RILEM [4] recommend a three-point bending test for determination of cementitious composites tensile strengths. The specimens are simply supported beams $150 \times 150 \times 550 \mathrm{~mm}$ with the notch $5 \mathrm{~mm}$ wide in the middle of span (Fig. 2a). The span of specimen in the test is $500 \mathrm{~mm}$. These dimensions don't affect the distribution of fibres in a fibre reinforced cementitious composite (it applies to metallic fibres with long up to $60 \mathrm{~mm}$ ). The test arrangement allows to record the load force - deflection dependence $(F-\delta)$ or the load force - crack opening dependence $(F-C M O D)$.

There are 2 ways, how to control the test:

a) through deflection: $v_{\mathrm{f}(\delta)}=0,2 \mathrm{~mm} / \mathrm{min}$ throughout the test

b) through crack opening:

$$
\begin{aligned}
& 1^{\text {st }} \text { stage: } v_{\mathrm{f}(\mathrm{CMOD}) 1}=0,05 \mathrm{~mm} / \mathrm{min} \text { until the crack opening } \triangle C M O D_{1}=0,1 \mathrm{~mm} \\
& 2^{\text {nd }} \text { stage: } v_{\mathrm{f}(\mathrm{CMOD}) 2}=0,2 \mathrm{~mm} / \mathrm{min} \text { until the end of the test }
\end{aligned}
$$

Four-point bending test. The un-notched beam specimens $150 \times 150 \times 700 \mathrm{~mm}$ are recommended for four-point bending test The span of beam is $600 \mathrm{~mm}$ and the beam is loaded by pair of load forces in thirds of this span (Fig. 2b). Between these forces there is a wide area with the same stress, so a failure will occur in the weakest place of the material.

The test should be controlled through a middle span deflection of specimen. The loading rate can be as follows:

a) $1^{\text {st }}$ stage: $v_{\mathrm{fl}}=0,01 \mathrm{~mm} / \mathrm{min}$ until the increase of deflection $\Delta \delta_{1}=0,2 \mathrm{~mm}$

$2^{\text {nd }}$ stage: $v_{\mathrm{f} 2}=0,2 \mathrm{~mm} / \mathrm{min}$ until the increase of deflection $\Delta \delta_{2}=6,0 \mathrm{~mm}$

$3^{\text {rd }}$ stage: $v_{\mathrm{f} 3}=0,5 \mathrm{~mm} / \mathrm{min}$ until the increase of deflection $\Delta \delta_{3}=10,0 \mathrm{~mm}$

b) regular loading: $v_{\mathrm{f}}=0,2 \pm 0,05 \mathrm{~mm} / \mathrm{min}$ until the deflection $\Delta \delta=4,0 \mathrm{~mm}$

The load force - middle span deflection dependence is recorded in the test, the output of the test is $\left(F_{\mathrm{R}}-\delta_{\mathrm{t}}\right)$ diagram. A valid test result is only the case, where the macrocrack occurs in the middle third of span, this is between the pair of load forces. 
a)

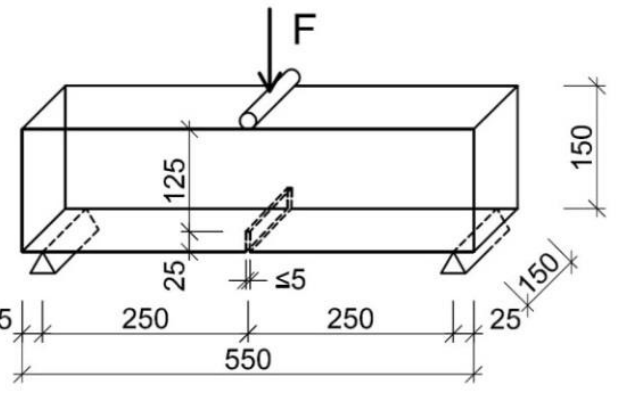

b)

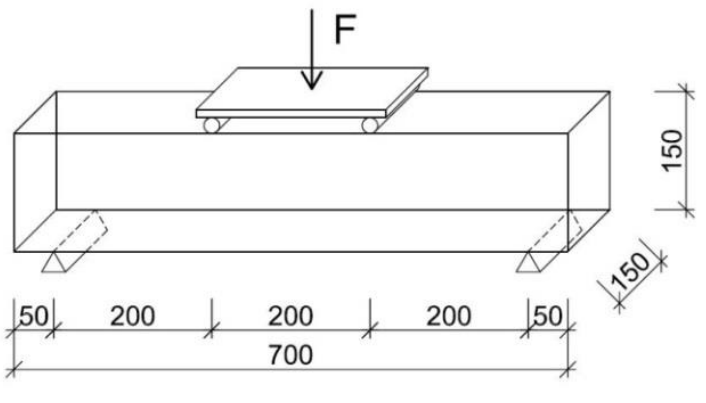

Fig. 2 Bending tests: a) three-point arrangement; b) four-point arrangement

Evaluation of bending tests. The evaluation of bending tests is necessary to divide into 2 parts:

a) before macrocracking

b) after macrocracking

Material behaviour before macrocracking can be considered quasilinear, it means that stress is directly proportional to strain.

In the three-point bending test the tensile strength of material at macrocracking can be calculated as:

$f_{\mathrm{t}, \mathrm{cr}}=\frac{3 \cdot F_{\mathrm{R}, \mathrm{cr}} \cdot L}{2 \cdot b \cdot h_{\mathrm{sp}}^{2}}$,

where $F_{\mathrm{R}, \mathrm{cr}}$ is value of load force at macrocracking, $L$ is span of specimen, $b$ is width of specimen cross-section and $h_{\mathrm{sp}}$ is residual height of specimen cross-section in the notch.

In the four-point bending test the tensile strength of material at macrocracking can be calculated as:

$$
f_{\mathrm{t}, \mathrm{cr}}=\frac{3 \cdot F_{\mathrm{R}, \mathrm{cr}} \cdot a}{b \cdot h^{2}},
$$

where $F_{\mathrm{R}, \mathrm{cr}}$ is value of load force at macrocracking, $a$ is distance between each of pair of load forces and the supports, $b$ and $h$ are width and height of specimen cross-section.

Assumption of quasilinear distribution of stress in the cross-section is not valid after macrocracking. The values of residual strengths must be quantified in another way:

a) numerical solution - incremental method

b) approximate solution - a material model choice after macrocracking

Numerical solution needs to calculate the position of neutral axis in each loading step on the basis of equilibrium of tensile and compressive forces in the cross-section. The state of stress in the previous step is taken into account (Fig. 3). This process is timely and numerically demanding and can't be done without advanced computing. Due to the discontinuities in the $\left(F_{\mathrm{R}}-\delta t\right)$ diagram, the record must first be slicked, otherwise the numerical calculation fails.

In the case of approximate solution an idealised model of material behaviour after macrocracking is chosen and the residual strength values at particular strain are calculated for the specific state and the known position of the neutral axis. The detailed procedure for this solution is described in the document [5]. 


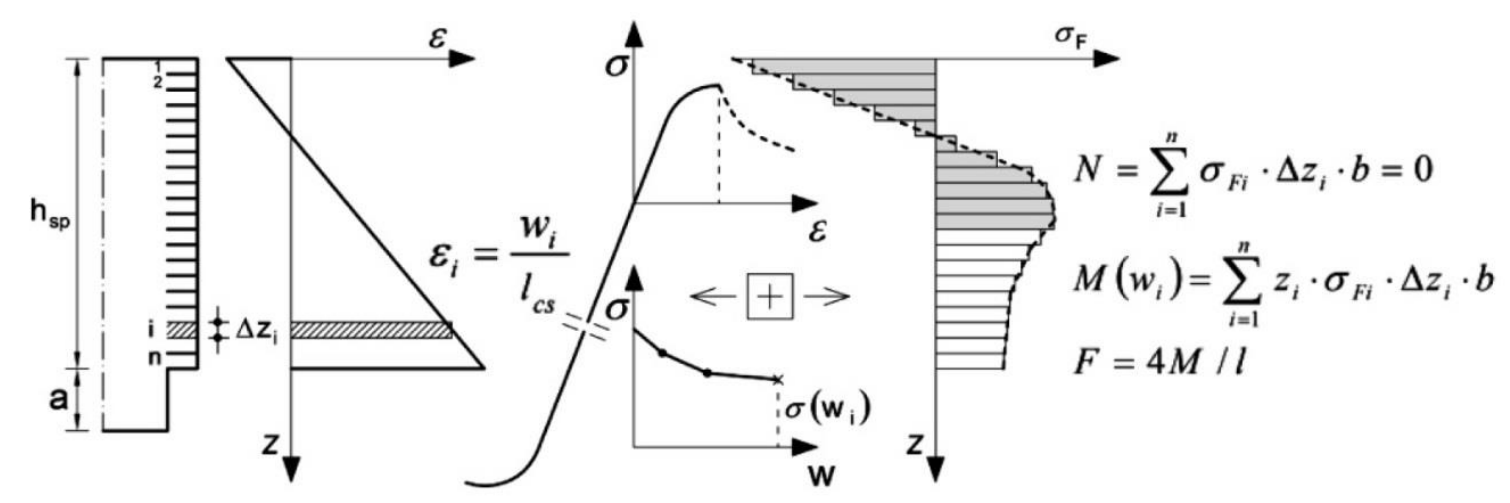

Fig. 3 Numerical solution of forces equilibrium in cross-section [3]

Comparison of three-point and four-point bending test. Both of bending tests described above show differences which bring particular advantages or disadvantages. The centre notch in three-point bending test affects a distribution of stress in its surroundings. Above all, the notch defines the point of failure (Fig. 4a), so it isn't respected the requirement to find the weakest material point. Therefore the three-point bending test shows higher values of material tensile strength, both at macrocracking and the residual.
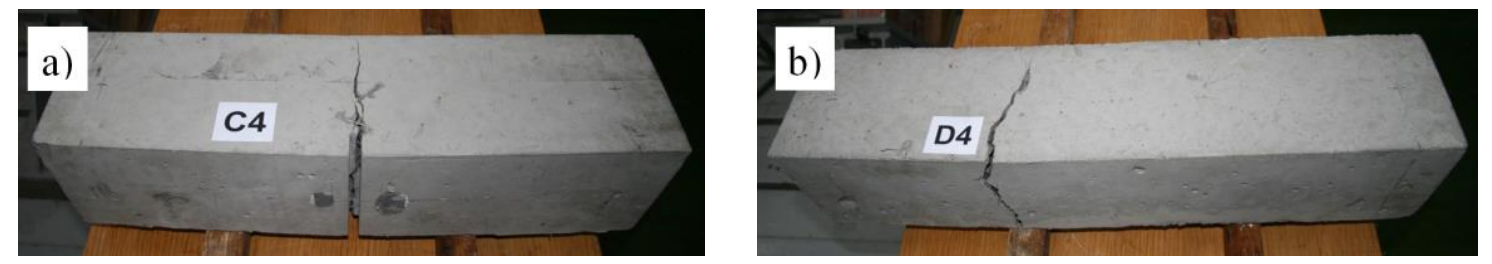

Fig. 4 Position of macrocrack: a) three-point bending test - in the notch;

b) four-point bending test - the weakest material point

On the other hand, the notch allows the installation of crack opening sensor (Fig. 5). In fourpoint bending test the crack opening must be measured using other methods (external scale, photogrammetry). The three-point bending test can also be controlled by crack opening rate due to this sensor.

A distribution of internal forces in the length of specimen is also an important factor, which influences the determination of material strength. The combination of bending moment and shear force causes a failure of specimen in three-point bending test (Fig. 6a). There is an area in the middle third of span in four-point bending test, where the shear force is zero and the critical crosssection is loaded only by the bending moment (Fig. 6b).

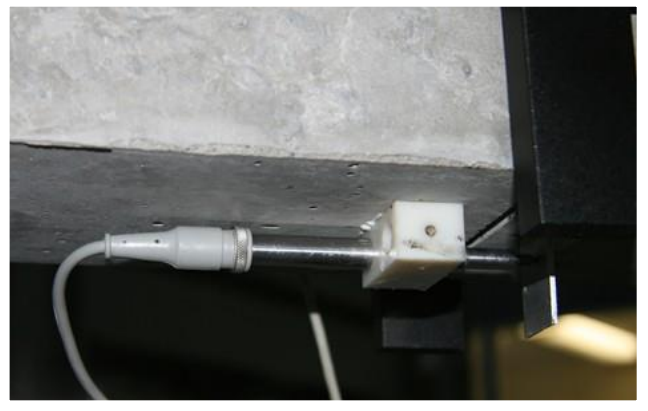

Fig. 5 The sensor for crack opening measurement a)

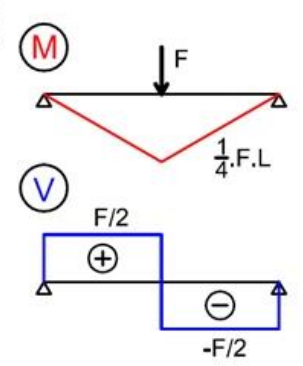

b)

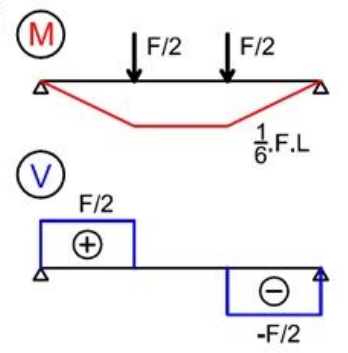

Fig. 6 Internal forces in bending tests: a) three-point bending; b) four-point bending 


\section{Axial tension tests}

The advantage of concrete and fibre reinforced concrete axial tension test is that it provides directly the strength values in pure tension. So it isn't necessary to derive them from other parameters. The disadvantages are its technical difficulty and the high sensitivity to introduced deformations.

Notched cylinder, glued fixation. The recommendation RILEM [6] uses cylindrical specimens with a diameter of $150 \mathrm{~mm}$ and with a $15 \mathrm{~mm}$ deep notch in the middle of height for axial tension test of concrete and fibre reinforced concrete (Fig. 7). The flat ends of specimen are bonded to the steel plates of the testing machine. Three extensometers are placed in the notch around the specimen. These extensometers measure notch opening and control the loading process.

The recommended loading rate is divided into 2 stages:

- $1^{\text {st }}$ stage: $v_{\mathrm{f}(\mathrm{CMOD}) 1}=0,005 \mathrm{~mm} / \mathrm{min}$ until the notch deformation $\delta=0,1 \mathrm{~mm}$

- $2^{\text {nd }}$ stage: $v_{\mathrm{f}(\mathrm{CMOD}) 2}=0,1 \mathrm{~mm} / \mathrm{min}$ until the notch deformation $\delta=2,0 \mathrm{~mm}$

The dependence of tension load force $F_{\mathrm{t}}$ on average notch opening $C M O D$ is recorded in the test.

The tensile strength, respectively tensile stress in material can be calculated in each phase of loading due to formula:

$$
\sigma_{\mathrm{ti}}=\frac{F_{\mathrm{ti}}}{A_{\text {eff }}}
$$

where $F_{\text {ti }}$ is value of load force in that loading phase and $A_{\text {eff }}$ is cross-section area of specimen in the notch.

This test arrangement is objective appropriate only for materials with softening behaviour after macrocracking. The notch doesn't allow forming multiple cracks, which is typical for material with hardening behaviour. Furthermore, the observed deformation area of the specimen is very small (notch width only $5 \mathrm{~mm}$ ), so inaccuracy of measurement have a more significant impact on the strain evaluation.

Dogbone specimen, mechanical fixation. An alternative arrangement of axial tension test for cementitious composites is using the specimens with variable cross-section - dogbone specimens [7]. One of these arrangements was developed and optimized at Department of concrete and masonry structures, Faculty of Civil Engineering, CTU in Prague in last years (Fig. 8). The end parts of the specimens have rectangular shape with basic dimensions and serve to mechanical fixation of specimen to the testing machine. The central part of specimen has a reduced crosssection and this is an area, where the failure is expected. The constant cross-section in this part allows finding a weakest place of the material and it leads to multiple cracking of material with hardening behaviour. A pair of extensometers is mounted on opposite specimen surfaces, so it is possible to record the dependence of load force $F_{\mathrm{t}}$ on the deformation of central part of specimen $\delta_{\mathrm{t}}$.

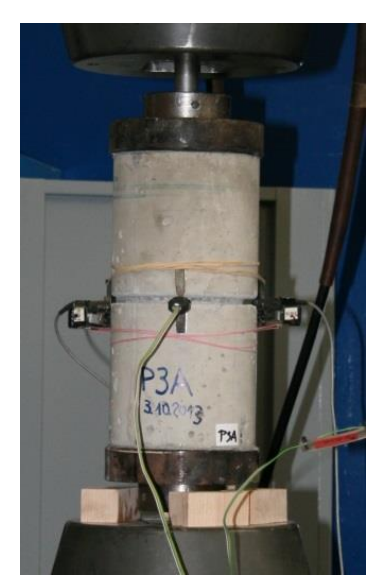

Fig. 7 Axial tension test - notched cylinder

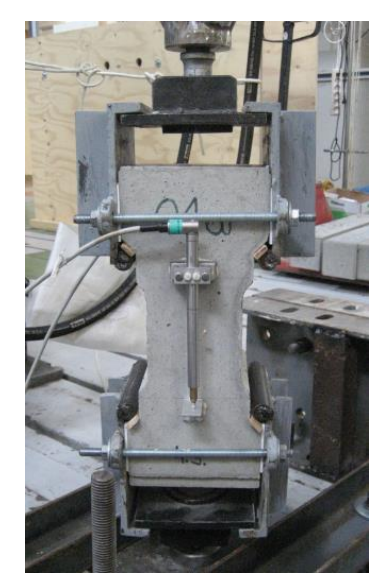

Fig. 8 Axial tension test - bog bone specimen 
The test is controlled through the deformation increase of the central part of specimen. The recommended loading rates are:

- $1^{\text {st }}$ stage: $v_{\mathrm{fl}}=0,005 \mathrm{~mm} / \mathrm{min}$ before macro cracking

- $2^{\text {nd }}$ stage: $v_{\mathrm{f} 2}=0,1 \mathrm{~mm} / \mathrm{min}$ after macro cracking

It is assumed a macrocrack formation in 3 to 5 minutes. The complete testing will take about 20 minutes.

The evaluation of material strengths is carried out in the same way as in the previous variant of the test (Eq. 5).

The evaluation of the strain assumes the redistribution of the normal rigidity of specimen, when micro- and macrocrack are forming and distributing. The value of material strain can be quantified in any loading phase according to:

$$
\varepsilon_{\mathrm{ti}}=\frac{\delta_{\mathrm{p} 1}}{L_{\mathrm{p} 1}}=\frac{\delta_{\mathrm{i}}-\delta_{\mathrm{A}}}{L_{\mathrm{p} 1}}=\frac{\delta_{\mathrm{i}}-\frac{F_{\mathrm{i}} \cdot\left(L_{\mathrm{sen}}-L_{\mathrm{p} 1}\right)}{B_{\mathrm{A}}}}{L_{\mathrm{p} 1}},
$$

where $\delta_{\mathrm{pl}}$ is value of deformation in macro crack area, $\delta_{\mathrm{1}}$ is average value of deformation given by the extensometers in any loading phase, $\delta_{\mathrm{A}}$ is the value of deformation out of the macro crack area, $L_{\mathrm{sen}}$ is distance between endpoints of extensometers, $L_{\mathrm{pl}}$ is length of macrocrack area, $F_{\mathrm{i}}$ is value of tension load force in any loading phase and $B_{\mathrm{A}}$ is normal rigidity out of the macrocrack area [2].

\section{Experimental comparison of tensile strengths}

The conversion factor between tension strengths of cementitious composites, which were determined in test described above, were quantified in experiments. The composites with the same cement matrix and different type and dose of fibres were tested. Three specimens for each recipe and for each test method were used. View of fibre dosing is shown in Table 1.

Table 1 Dosage of fibres of partial recipes

\begin{tabular}{|c|c|c|c|c|c|c|c|}
\hline \multirow{3}{*}{\multicolumn{2}{|c|}{ Recipe }} & \multicolumn{3}{|c|}{ Fibres 1} & \multicolumn{3}{|c|}{ Fibres 2} \\
\hline & & \multirow{2}{*}{ Type of fibres } & \multicolumn{2}{|c|}{ dose } & \multirow{2}{*}{ Type of fibres } & \multicolumn{2}{|c|}{ dose } \\
\hline & & & {$\left[\mathrm{kg} / \mathrm{m}^{3}\right]$} & [\%] & & {$\left[\mathrm{kg} / \mathrm{m}^{3}\right]$} & [\%] \\
\hline 1 & reference concrete & - & - & - & - & - & - \\
\hline 2 & $0,5 \% \mathrm{TT}$ & TriTreg 50/1,05mm & 39,3 & 0,5 & - & - & - \\
\hline 3 & $1,0 \% \mathrm{TT}$ & TriTreg 50/1,05mm & 78,5 & 1,0 & - & - & - \\
\hline 4 & $1,0 \% \operatorname{Dr} 80 / 60$ & Dramix RC 80/60 BN & 78,5 & 1,0 & - & - & - \\
\hline 5 & $3,0 \% \mathrm{TT}+\mathrm{Fib}$ & TriTreg 50/1,05mm & 117,8 & 1,5 & Fibrex A1 & 117,8 & 1,5 \\
\hline 6 & $0,64 \% \operatorname{Dr} 65 / 60$ & Dramix 5D 65/60 BG & 50,0 & 0,64 & - & - & - \\
\hline
\end{tabular}

Documents $[1,3,4,5]$ give the values of conversion factor to tensile strength in pure tension, which are uniform for all types of fibre-cementitious materials. However, the results of the experiments show that these values are highly dependent on the type and dose of using fibres and probably also on the composition of concrete matrix. The average values of determined strengths at macrocracking for tested recipes are shown in Table 2. The values of strengths and conversion factors after macrocracking are shown in Table 3. 
Table 2 Average values of tensile strengths at macrocracking

\begin{tabular}{|c|c|c|c|c|c|c|c|c|c|c|}
\hline \multirow{2}{*}{\multicolumn{2}{|c|}{ Recipe }} & \multicolumn{2}{|c|}{$\begin{array}{l}\text { splitting test } \\
\text { cube } \\
150 \times 150 \times 150 \mathrm{~mm}\end{array}$} & \multicolumn{2}{|c|}{$\begin{array}{l}\text { 3-point bending } \\
\text { notched beam } \\
150 \times 150 \times 600 \mathrm{~mm}\end{array}$} & \multicolumn{2}{|c|}{$\begin{array}{l}\text { 4-point bending } \\
\text { un-notched beam } \\
150 \times 150 \times 700 \mathrm{~mm}\end{array}$} & \multicolumn{2}{|c|}{$\begin{array}{l}\text { axial tension } \\
\text { notched cylinder } \\
150 \times 300 \mathrm{~mm}\end{array}$} & \multirow{2}{*}{$\begin{array}{c}\begin{array}{c}\text { axial tension } \\
\text { dogbone } \\
146 \times 150 \times 349 \mathrm{~mm}\end{array} \\
f_{\mathrm{t}, \mathrm{cr}, \mathrm{ax}} \\
{[\mathrm{MPa}]}\end{array}$} \\
\hline & & $\begin{array}{c}f_{\mathrm{t}, \mathrm{cr}, \mathrm{sp}} \\
{[\mathrm{MPa}]}\end{array}$ & $\begin{array}{c}f_{\mathrm{t}, \mathrm{cr}, \mathrm{sp}} \\
/ f_{\mathrm{t}, \mathrm{cr}, \mathrm{ax}}\end{array}$ & $\begin{array}{r}f_{\mathrm{t}, \mathrm{cr}, 3 \mathrm{~B}} \\
{[\mathrm{MPa}]}\end{array}$ & $\begin{array}{c}f_{\mathrm{t}, \mathrm{cr}, 3 \mathrm{~B}} \\
/ f_{\mathrm{t}, \mathrm{cr}, \mathrm{ax}}\end{array}$ & $\begin{array}{l}f_{\mathrm{t}, \mathrm{cr}, 4 \mathrm{~B}} \\
{[\mathrm{MPa}]}\end{array}$ & $\begin{array}{c}f_{\mathrm{t}, \mathrm{cr}, 4 \mathrm{~B}} \\
/ f_{\mathrm{t}, \mathrm{cr}, \mathrm{ax}}\end{array}$ & $\begin{array}{c}f_{\mathrm{t}, \mathrm{cr}, \mathrm{ax}, \mathrm{cyl}} \\
{[\mathrm{MPa}]}\end{array}$ & $\begin{array}{l}f_{\mathrm{t}, \mathrm{cr}, \mathrm{ax}, \mathrm{cyl}} \\
/ f_{\mathrm{t}, \mathrm{cr}, \mathrm{ax}}\end{array}$ & \\
\hline 1 & reference concrete & 3.60 & 1.32 & 4.87 & 1.79 & 4.84 & 1.78 & 3.37 & 1.24 & 2.72 \\
\hline 2 & $0,5 \% \mathrm{TT}$ & 4.45 & 1.29 & 5.18 & 1.51 & 4.82 & 1.40 & 3.83 & 1.11 & 3.44 \\
\hline 3 & $1,0 \%$ TT & 4.70 & 1.33 & 5.93 & 1.68 & 5.55 & 1.57 & 4.06 & 1.15 & 3.53 \\
\hline 4 & $1,0 \% \operatorname{Dr} 80 / 60$ & 6.20 & 1.53 & - & - & 6.30 & 1.55 & - & - & 4.06 \\
\hline 5 & $3,0 \% \mathrm{TT}+\mathrm{Fib}$ & 8,80 & 1.78 & - & - & 6.48 & 1.44 & - & - & 4.50 \\
\hline 6 & 0,64\% Dr 65/60 & - & - & - & - & 5.17 & 1.58 & - & - & 3.28 \\
\hline \multicolumn{2}{|c|}{ Standards: } & & 1.18 & & 1.67 & & 1.45 & & 1.00 & \\
\hline
\end{tabular}

The ratios strengths in splitting test $f_{\mathrm{t}, \mathrm{cr}, \mathrm{sp}}$ and axial tension test $f_{\mathrm{t}, \mathrm{cr}, \mathrm{ax}}$ are in the range that considerably exceeds the conversion factors given in document [1]. It is also clear that this ratio increases with the strength of the material, it means with dose and efficiency of fibres.

The three-point bending test shows in all cases higher strengths at macrocracking than the fourpoint bending test. The strength ratios of bending test to axial tension test are in relation, which are given in documents [4,1]. Dependence on fibre dose was not confirmed.

The axial tension test with notched cylinders shows slightly higher strength values at macrocracking than the axial tension test with dogbone specimens.

Table 3 Average values of residual tensile strengths depending on strain

\begin{tabular}{|c|c|c|c|c|c|c|c|c|c|c|}
\hline \multirow{2}{*}{$\mathcal{E}_{\mathrm{t}, \mathrm{res}}$} & \multirow{2}{*}{\multicolumn{2}{|c|}{ Recipe }} & \multicolumn{3}{|c|}{$\begin{array}{l}\text { 3-point bending } \\
\text { notched beam } \\
150 \times 150 \times 600 \mathrm{~mm}\end{array}$} & \multicolumn{2}{|c|}{$\begin{array}{l}\text { 4-point bending } \\
\text { un-notched beam } \\
150 \times 150 \times 700 \mathrm{~mm}\end{array}$} & \multicolumn{2}{|c|}{$\begin{array}{l}\text { axial tension } \\
\text { notched cylinder } \\
150 \times 300 \mathrm{~mm}\end{array}$} & \multirow{2}{*}{$\begin{array}{c}\begin{array}{c}\text { axial tension } \\
\text { dogbone } \\
146 \times 150 \times 349 \mathrm{~mm}\end{array} \\
f_{\mathrm{t}, \mathrm{ax}}[\mathrm{MPa}]\end{array}$} \\
\hline & & & $\begin{array}{c}f_{\mathrm{t}, 3 \mathrm{~B}} \\
{[\mathrm{MPa}]}\end{array}$ & $\begin{array}{c}f_{\mathrm{t}, 3 \mathrm{~B}} / \\
f_{\mathrm{t}, \mathrm{ax}}\end{array}$ & $\begin{array}{c}f_{\mathrm{t}, 3 \mathrm{~B}} / \\
f_{\mathrm{t}, 4 \mathrm{~B}}\end{array}$ & $\begin{array}{c}f_{\mathrm{t}, 4 \mathrm{~B}} \\
{[\mathrm{MPa}]}\end{array}$ & $\begin{array}{c}f_{\mathrm{t}, 4 \mathrm{~B}} \\
/ f_{\mathrm{t}, \mathrm{ax}}\end{array}$ & $\begin{array}{l}f_{\mathrm{t}, \mathrm{ax}, \mathrm{cyl}} \\
{[\mathrm{MPa}]}\end{array}$ & $\begin{array}{l}f_{\mathrm{t}, \mathrm{ax}, \mathrm{cyl}} \\
/ f_{\mathrm{t}, \mathrm{ax}}\end{array}$ & \\
\hline \multirow{4}{*}{$\begin{array}{l}\text { de } \\
0 \\
\text { i }\end{array}$} & 2 & 0,5\% TT & 1.62 & - & 1.11 & 1.46 & - & 0 & - & 0 \\
\hline & 3 & 1,0\% TT & 2.86 & 2.42 & 1.26 & 2.27 & 1.92 & 1.20 & 1,02 & 1.18 \\
\hline & 4 & $1,0 \% \operatorname{Dr} 80 / 60$ & - & - & - & 3.28 & 2.34 & - & - & 1.40 \\
\hline & 5 & $3,0 \%$ TT+Fib & - & - & - & 3.43 & 1.54 & - & - & 2.23 \\
\hline \multirow{4}{*}{$\begin{array}{l}d^{\circ} \\
0 \\
i\end{array}$} & 2 & 0,5\% TT & 1.44 & - & 1.12 & 1.29 & - & 0 & - & 0 \\
\hline & 3 & 1,0\% TT & 2.64 & 2.34 & 1.10 & 2.41 & 2.13 & 1.18 & 1,04 & 1.13 \\
\hline & 4 & $1,0 \% \operatorname{Dr} 80 / 60$ & - & - & - & 3.67 & 2.22 & - & - & 1.65 \\
\hline & 5 & $3,0 \%$ TT+Fib & - & - & - & 3.17 & 1.46 & - & - & 2.17 \\
\hline \multirow{4}{*}{$\begin{array}{l}0 \\
0 \\
0\end{array}$} & 2 & 0,5\% TT & 1.31 & - & 1.17 & 1.12 & - & 0 & - & 0 \\
\hline & 3 & 1,0\% TT & 2.39 & 2.28 & 1.06 & 2.26 & 2.15 & 1.13 & 1,08 & 1.05 \\
\hline & 4 & $1,0 \% \operatorname{Dr} 80 / 60$ & - & - & - & 3.50 & 2.35 & - & - & 1.49 \\
\hline & 5 & $3,0 \% \mathrm{TT}+\mathrm{Fib}$ & - & - & - & 2.69 & 1.43 & - & - & 1.88 \\
\hline \multirow{4}{*}{$\begin{array}{l}\stackrel{8}{d} \\
\stackrel{2}{0}\end{array}$} & 2 & 0,5\% TT & 1.11 & - & 1.13 & 0.98 & - & 0 & - & 0 \\
\hline & 3 & 1,0\% TT & 1.98 & 2.08 & 1.08 & 1.83 & 1.93 & 1.02 & 1,07 & 0.95 \\
\hline & 4 & $1,0 \% \operatorname{Dr} 80 / 60$ & - & - & - & 2.98 & 2.29 & - & - & 1.30 \\
\hline & 5 & $3,0 \% \mathrm{TT}+\mathrm{Fib}$ & - & - & - & 1.84 & 1.67 & - & - & 1.10 \\
\hline \multicolumn{3}{|c|}{ Standards: } & & 1.67 & & & 1.45 & & 1.00 & \\
\hline
\end{tabular}


The differences in tests are quite individual after macrocracking. The ratios of residual strengths in bending tests and axial tension test are significantly higher than the documents [4] and [1] give. Conversely, both tests in axial tension have shown approximately the same strength values. The unambiguous trend of dependence of the conversion factors on material strain was not observed. Detailed results of the experiments and their interpretation are presented in the document [2].

\section{Conclusion}

Various test methods can be used to determine the tensile strengths of concrete and fibre reinforced concrete, but the results must be correctly interpreted. Experiments have shown that the conversion factors between strength values derived in the individual tests are not constant for all composite recipes and also shown differences depending on the material stain values. If the tensile strength values of fibre reinforced concrete are derived in other test than in axial tension test, it is first necessary to experimentally derive conversion factors for a given recipe.

\section{Acknowledgement}

Research presented in this paper was supported by grant projects SGS17/049/OHK1/1T/11 "Fibre Reinforced Concrete with Specific Structures - Behavioural Analysis and Applications" and GA 1608937S "State of stress and strain of fibre reinforced composites in interaction with the soil environment".

\section{References}

[1] ČSN P 73 2452: Fibre-reinforced concrete - Testing of hardened fibre-reinforced concrete. ÚNMZ, Prague, 2015.

[2] M. Tipka, Tensile Properties of Structural Fibre Reinforced Concrete, Ph.D. Thesis, CTU in Prague, Faculty of Civil Engineering, Prague, 2017.

[3] Model Code for Concrete Structures 2010. International Federation for Structural Concrete (fib), Lausanne, Switzerland, 2013.

[4] RILEM TC 162-TDF: Test and design methods for steel fibre reinforced concrete: Bending test. Final recommendation, in: Materials and Structures, Vol. 35, 2002.

[5] RILEM TC 162-TDF: Test and design methods for steel fibre reinforced concrete: $\sigma$ - $\varepsilon$-design methods. Final recommendation, in: Material and Structures, Vol. 36, 2003.

[6] RILEM TC 162-TDF: Test and design methods for steel fibre reinforced concrete: Uni-axial tension test for steel fibre reinforced concrete, in: Material and Structures, Vol. 34, 2001.

[7] M. Tipka, J. Vašková, Issues of Testing of Cementitious Composites in Uniaxial Tension, in: Proceedings from $22^{\text {nd }}$ Czech Concrete Day 2015, Solid State Phenomena, Pfäffikon, Switzerland, 2016. 